\title{
Aplikasi Model Pembelajaran Kooperatif Tipe Team Assisted Individualization (TAI) dengan Tutor Sebaya untuk Meningkatkan Prestasi Belajar Matematika
}

\author{
I Wayan Mertayasa ${ }^{1 *}$ \\ SD Negeri 2 Tianyar Barat, Bali, Indonesia
}

\section{ART I CLE I N F O}

Article history:

Received March 16, 2021

Revised March 25, 2021

Accepted June 20, 2021

Available online August 25, 2021

Kata Kunci:

Model Pembelajaran Kooperatif Tipe (TAI), Tutor Sebaya, Prestasi Belajar

Keywords:

Type of Cooperative Learning Model (TAI), Peer Tutor, Learning

Achievement

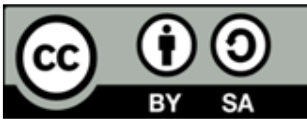

This is an open access article under the CC BY-SA license.

Copyright $(2021$ by Author. Published by Universitas Pendidikan Ganesha.

\begin{abstract}
A B S T R A K
Rendahnya prestasi belajar matematika akibat penerapan model pembelajaran yang masih kurang inovatif. penerapan model pembelajaran yang kurang inovatif akan menyebabkan siswa bosan dan menggap pelajaran matematika itu sulit. Oleh sebab itulah penelitian yang bertujuan untuk mengkaji Aplikasi Model Pembelajaran Kooperatif Tipe Team Assisted Individualization (TAI) dengan Tutor Sebaya untuk Meningkatkan Prestasi Belajar Matematika. Jenis penelitian tindakan kelas dengan 2 siklus. Subjek penelitian ini adalah siswa kelas $\mathrm{V}$ yang mendapatkan pembelajaran Matematika. Metode pengumpulan data yang digunakn adalah tes dan observasi. Metode analisis datanya adalah deskriptif. Hasil yang diperoleh dari penelitian ini adalah prestasi belajar siswa dapat ditingkatkan dengan menerapkan langkah-langkah model pembelajaran Kooperatif Tipe Team Assissted Individualization (TAI) dengan Tutor Sebaya. Ini terbukti dari hasil yang diperoleh pada awalnya 56.25, pada siklus I meningkat menjadi 58,13 dan pada Siklus II meningkat menjadi 75 . Jadi, prestasi belajar siswa dapat ditingkatkan dengan menerapkan langkah-langkah model pembelajaran Kooperatif Tipe Team Assissted Individualization (TAI) dengan Tutor Sebaya.
\end{abstract}

\section{A B S T R A C T}

The assessment instrument applied is less accurate, resulting in difficulties for teachers and parents to detect developmental barriers experienced by children, especially in the physical aspects of children's gross motor development. Teachers have difficulty in making good assessment instruments. This study aimed to develop an assessment instrument for gross motoric developmental barriers in early childhood. This research and Development (RnD) using a development model, namely RDR developed by Brog\&Gall. The subjects of this research are four experts. The test subjects in this study amounted to 20 students. Data collection methods in this study are interviews and questionnaires. The instrument used in collecting data is a questionnaire. They are testing the instrument through validity and reliability the instrument. Instrument Reliability Analysis uses the Percentage of Agreement formula. The study results are the results of the content validity of the assessment instrument for physical development barriers in children's gross motor skills of 1.00 with very high validity criteria. The result of the instrument reliability test is 1.00, so it is declared reliable. Based on the instrument's validity analysis, it can be concluded that the assessment instrument for gross motoric developmental barriers in early childhood is appropriate for use in the learning process. This research implies that the instrument can be used by teachers in measuring gross motoric physical development in early childhood.

\section{PENDAHULUAN}

Pembelajaran yang baik adalah pembelajarn yang memberikan gambran yang jelas tentang bagaimana siswa belajar. Pembelajaran yang berkulitas akan sangat mempengaruhi hasil belajar peserta didik. Hasil belajar adalah segala hasil yang diperoleh dari proses belajar baik pengetahuan, sikap, dan 
keterampilan. Tentunya hasil ini tidak akan baik jika proses pembelajaran yag dilakukan tidak sesaui dengan yang diharapkan. Pembelajaran haruslah memberikan kesempatan kepada peserta didik untuk membangun pengetahunya sendiri sehingga pembelajaran lebih bermakna. Pembelajaran bermakna akan diperoleh dari proses pembelajaran yang mengaktifkan siswa misalnya dari praktikum atau pembelajaran berbasis penemuan (Angela, 2014; Bressington, Wong, Lam, \& Chien, 2018) yang memberikan pengalaman yang nantinya bisa digunakan dalam kehidupan sehari-hari. tentunya disini peran guru sangat penting dalam merancang pembelajaran dan dalam melaksanakan proses pembelajaran. dalam proses merancang pembelajaran model pembelajaran tidak bisa dipisahkan karena dengan adanya model pembelajaran inovatif akan membuat peserta didik belajar lebih aktif. Model pembelajaran yang dipandang mampu memberi harapan dan memperbaiki situasi belajar peserta didik (Muhammad, 2018). Beberapa model pembelajaran yang digunakan adalah untuk meningkatkan hasil belajar adalah model pembelajaran kooperatif.

Pembelajaran kooperatif akan memberikan dampak positif terhadap kemampuan siswa dalam proses pembelajaran. Model pembelajaran kooperatif akan dapat menumbuhkan pembelajaran efektif (Lisdayanti, Ardana, \& Suryaabadi, 2014). Model pembelajaran kooperatif yang mudah diterapkan melibatkan aktivitas seluruh siswa tanpa harus ada perbedaan status melibatkan (Suaeb, Degeng, \& Amirudin, 2018). Model pembelajaran kooperatif bukan hanya memberikan siswa tugas kelompok melainkan kegiatan pembelajaran kooperatif memberikan aktivitas saling mendukung antar siswa (Arthaningsih \& Diputra, 2018). Model pembelajaran kooperatif memiliki tujuan untuk membantu siswa bekerja dalam diskusi kelompok dan siswa mempunyai kesempatan yang sama serta untuk memastikan semua anggota telah belajar (Puspitawangi, Wibawa, \& Pudjawan, 2017; Seika Ayuni, Kusmariyatni, \& Japa, 2017). Penerapan model pembelajaran kooperatif sesaui dengan langkah-langkah dan prinsipnya akan berdampak terhadap hasil belajar (Kurniawati, Budiyono, \& Saputro, 2017; Shoffa \& Suprapti, 2017), serta dapat meningkatkan motivasi siswa (Nurmahmidah, 2017). Jadi, jabaran tersebut memberikan gambaran bahwa pembelajaran kooperatif akan membuat siswa lebih aktif, termotivasi dan lebih mengaktifkan kerja sama antar peserta didik.

Namun, hambatan-hambatan yang ditemukan di lapangan antara lain adalah kelas selalu pasif akibat dominasi guru dalam pembelajaran, motivasi siswa untuk belajar sangat rendah. Akibat mereka lebih senang bermain, selanjutnya menumbuhkan interaksi baik antara siswa dengan siswa maupun antara siswa dengan guru. Dalam pelaksanaan pembelajaran guru bersifat monoton, tidak menggunakan strategi pembelajaran yang tepat dalam pembelajaran, tidak menggunakan model-model yang rekomentasikan para ahli pendidikan, tidak pernah mau merubah paradigma pendidikan dari pengajaran menjadi pembelajaran, sehingga proses pembelajaran terus berhari-hari itu-itu saja, sampai sudah basi juga begitu-begitu saja. Kondisi ini didukung oleh hasil studi awal yang menyatakan bahwa rata-rata nilai yang diperoleh siswa baru 56,25 rata-rata tersebut masih jauh di bawah KKM mata pelajaran Matematika di sekolah ini yaitu 60, Dari kegiatan yang dilakukan terdapat beberapa permasalahan dalam pembelajaran. Permasalahan tersebut di antaranya adalah: 1) rendahnya kesiapan siswa untuk mengikuti pelajaran, 2) guru kurang komunikatif, 3) siswa yang kemampuannya kurang, terlihat belum siap belajar,4) siswa tidak mempunyai motivasi dalam mengikuti proses pembelajaran, 5) guru belum membiasakan peserta didik belajar secara kooperatif dan kolaboratif, 6) guru masih mengajar dengan model konvensional. Kondisi ini juga didukung oleh hasil penelitian yang menyatakan pendapat yang sama bahwa saat ini masih banyak guru hanya mengunkan model pembelajaran langsung dengan metode ceramah. Guru meningkatkan prestasi belajar siswa guru juga kesulitan ketika berusaha untuk dalam proses pembalajaran. Disisis lain diinginkan, lebih-lebih tanpa menggunakan siswa masih jauh dari standar yang mengingat tingkat kecerdasan rata-rata model yang tepat dalam pembelajaran (Nurmahmidah, 2017). Siswa tidak mampu menguraikan secara sistematis jawaban mereka meskipun memperoleh hasil akhir yang benar (Muliandari, 2019). Proses pembelajaran masih dilakukan secara klasikal atau kelompok besar (Laksmi, Wiarta, \& Made Putra, 2017). Kondisi ini jika dibiarakan tentunya akan berdampak terhadap kualitas pembelajaran. jika dibiarakan dakan berdampak terhadap kualitas pendidikan.

Mengatasi masalah tersebut maka perlu dilakukan diterapkan model pembelajaran yang lebih inovatif yaitu model koopertaif tipe TAI. Model pembelajaran Kooperatif tipe TAI adalah salah satu model pembelajaran yang memadukan antara pembelajaran individu dan pembelajaran kelompok (Ariani, 2017). Adanya model pembelajaran ini dapat meningkatkan motivasi belajar siswa, melatih siswa untuk bekerja secara kelompok, dan juga dapat mengurangi anggapan bahwa pembelajaran itu sulit (Jaziroh, 2019). Pembelajaran tipe TAI tersebut, guru dapat meningkatkan kemampuan berpikir kritis dan aktivitas siswa untuk menjadi lebih aktif (Ngilamele, Laamena, \& Palinussa, 2019). Serta melalui pembelajaran TAI siswa diajak untuk belajar mandiri, dilatih untuk mengoptimalkan kemampuannya dalam mendapatkan informasi ilmiah yang dicari, dilatih menjelaskan hasil temuannya kepada pihak lain dan dilatih untuk 
memecahkan masalah, tidak hanya menerima, mendengar, dan mengingat saja (Hurriyah, 2017; Isa, Khaldun, \& Halim, 2017; Ujianti, 2019). Jabaran tersebut memberikan gambran bahwa model kooperatif tipe TAI akan membantu siawa untuk menemukan pengelamanya sendiri. Kelebihan model pembelajaran ini membuat beberapa peneliti melakukan penelitian untuk membuktikan efektifitas model pemelajaran Koopeartif Tipe TAI. Hasil penelitian menyatakan bahwa model pembelajaran kooperatif tipe Team Asissted Individualization (TAI) terhadap hasil belajar fisika siswa (Ariani, 2017; Hidayati, Deswita, \& Afri, 2016; Ngilamele et al., 2019). Selain itu model Team Asissted Individualization (TAI) dapat meningkatkan motivasi dan keatifan siswa dalam proses pembelajaran. Selain model pembelajaran teman sebaya sangat berpengaruh terhadap proses pembelajara.

Hubungan yang baik antara teman sebaya akan sangat efektif sebagai strategi untuk menarik minat anak dalam proses pembelajaran. Pembelajaran dengan teman sebaya akan mendorong peserta didik untuk berperan aktif dalam pembelajaran (Oh, 2019). Metode teman sebaya meningkatakan pembelajaran sendiri, peserta didik melalui pengalaman yang merupakan umpan balik dari temannya (Gabriele, Holthaus, \& Boulet, 2016). Teman sebaya membantu, membimbing dan mendukung sesama teman sebaya sehingga mereka mampu membangun pembelajaran melalui interaksi dan kolaborasi (Andersen \& Watkins, 2018). Pembelajaran yang melibatkan teman sebaya akan mengurangi kecemasan dan setres, dengan dibimbing, dibantu, dan diberikan umpan balik oleh teman sebaya peserta didik akan dapat meningkatkan kepercayaan diri (Han, Baek, \& Jeong, 2015; Stone, Cooper, \& Cant, 2013). Berdasarkan jabaran-jabaran tersebut, untuk menciptakan pembelajaran yang kondusif dan sesaui dengan kondisi saat ini, haruslah pembelajaran yang memberikan kesempatan kepada peserta didik untuk berbagi harapan belajar. Karena dengan peserta didik berbagi apa yang akan mereka pelajari dan saling mempengaruhi itu akan membuat proses pembelajaran mengembangakan interaksi dan kolaborasi peserta didik. jabaran tersebut memberikan gambaran bahwa baik model pembelajaran TAI dan tutor sebaya akan memberikan dampak positif terhadap hasil belajar. Oleh sebab itu tujuan penelitian ini adalah untuk mengkaji Aplikasi Model Pembelajaran Kooperatif Tipe Team Assisted Individualization (TAI) dengan Tutor Sebaya untuk Meningkatkan Prestasi Belajar Matematika. Dengan adanya model ini akan dapat meningkatakan dan mengatasi masalah yang berkaitan dengan prestasi belajar.

\section{METODE}

Jenis penelitian yang dilakukan tergolong penelitian tindakan kelas (classroom action research). Penelitian dilakukan di Satuan Pendidikan SD Negeri 2 Tianyar Barat,Kecamatan Kubu,Kabupaten Karangasem ,provinsi Bali. Dalam penelitian ini dilakukan dengan dua siklus. Masing-masing siklus dalam penelitian ini terdiri dari perencanaan, pelaksanaan, observasi/pengamatan dan refleksi. Rancangan mengenai siklus tersebut menggunakan model dari Depdiknas. Yang ditunjukkan pada gambar 1 . Subjek Penelitian dalam penelitian ini adalah Peserta didik yang belajar di kelas VI SD Negeri 2 tianyar Barat dijadikan subjek penelitian. Adapun objek dalam penelitian ini adalah peningkatan prestasi belajar Matematika siswa kelas VI SD Negeri 2 Tianyar Barat setelah diterapkan model pembelajaran Kooperatif tipe Team Assisted Individualization Dengan Tutor Sebaya. Adapun pelaksanaan penelitian tindakan kelas ini dimulai dari bulan Juli sampai bulan November 2019. Data hasil penelitian ini dikumpulkan dengan tes prestasi belajar. Adapun data hasil penelitian ini yang dipergunakan dalam menganalisis adalah analisis deskriptif. Untuk data kuantitatif dianalisis dengan mencari mean, median, modus, membuat interval kelas dan melakukan penyajian dalam bentuk tabel dan grafik. Sebuah penelitian sangat perlu menyampaikan apa yang digunakan untuk mencari data. Pentingnya hal tersebut tidak boleh ditawartawar, sehingga penggunaan tes prestasi belajar tidak bisa dipungkiri sebagai instrumennya. terlampir di masing-masing RPP pada lampiran. Indikator keberhasilan penelitian yang diusulkan dalam penelitian ini pada siklus I mencapai nilai rata-rata 58,13 dengan ketuntasan belajar $62,50 \%$ dan pada siklus II mencapai nilai rata-rata 75 dengan ketuntasan belajar 87,5\%.

Langkah-lankah kegiatan yang dilakukan antara lain Siklus I yang terdiri dari tahap 1. Rencana Tindakan I. Hal-hal yang menjadi perencanaan dari penelitian ini adalah: 1) Memahami lebih dalam sintaks pembelajaran yang digunakan; 2) Membaca materi dengan seksama sebelum mengajar agar tidak dalam pelaksanaannya terjadi hal-hal yang kurang diinginkan; 3) Menyiapkan alat peraga serta alat-alat lain yang akan mendukung proses pembelajaran pada saat pelaksanaannya; 4) Kelemahan siswa yang tidak aktif dicermati, diperbaiki dengan memberi tugas yang mampu dikerjakan; 5) Merencanakan dalam penutupan pembelajaran akan melakukan hal-hal: membuat ringkasan/rangkuman, melakukan peninjauan terhadap apa yang belum dipahami peserta didik, mendemonstrasikan ulang hal-hal yang belum betul dipahami, mengekspresikan, memberi soal-soal, memberikan tindak lanjut seperti pekerjaan rumah atau tugas-tugas tertentu. 2. Pelaksanaan Tindakan I. Hal-hal yang dilaksanakan dalam penelitian ini adalah: 1) Masuk ke kelas dengan berpakaian rapi, bersih dan sopan, 2) Mendorong semangat belajar 
siswa, 3) Menuntun siswa melakukan pembelajaran sesuai model yang digunakan, 4) Mengupayakan agar volume dan intonasi suara guru dapat didengar dengan baik oleh peserta didik, 5) Mengakhiri pelajaran tepat waktu dan menyampaikan salam penutup. 3 Observasi/Pengamatan Siklus I. Observasi atau pengumpulan data dari kegiatan penelitian ini dilakukan dengan cara: 1) Menjelaskan tentang observasi yang dilakukan, 2) Tes yang diberikan sudah tersusun baik sesuai perencanaan, 3) Menyuruh peserta didik untuk menanda tangani daftar hadir mengikuti tes, 4) Peneliti berputar-putar di kelas mengawasi dengan ketat pelaksaaan tes agar tidak ada siswa yang bekerja sama. 5) Memberikan penilaian dengan mencari skor merata. Dan 4. Refleksi Siklus I. Refleksi merupakan kajian secara menyeluruh tindakan yang telah dilakukan berdasarkan data yang telah terkumpul, kemudian dilakukan evaluasi guna menyempurnakan tindakan.

Langkah Siklus II yang terdiri atas 1. Rencana Tindakan II. Perencanaan merupakan barometer tentang apa yang akan dilaksanakan oleh seorang peneliti. Dengan begitu pentingnya sebuah perencanaan maka peneliti mencoba kemampuan yang dimiliki untuk menyusun perencanaan yang berisi: 1) Memahami lebih dalam sintaks pembelajaran yang digunakan, 2) Merencanakan mengatur tempat duduk siswa agar terjadi interaksi antara yang pandai dengan yang kurang pandai,3) Merencanakan pembelajaran yang menggunakan diskusi kelompok kecil yang dibantu dengan diskusi perorangan, 4) Membaca materi dengan seksama sebelum mengajar agar tidak dalam pelaksanaannya terjadi hal-hal yang kurang diinginkan, 5) Merencanakan kegiatan yang meksimal melalui kegiatan aktif bertanya, aktif memberi masukan, aktif memberi saran, dll. 2. Pelaksanaan Tindakan II. Pertimbangan yang baik dalam melaksanakan sebuah penelitian adalah arah-arah yang benar sesuai aturan. Untuk itu peneliti telah melaksanakannya melalui kegiatan-kegiatan diantaranya yaitu: 1) Memulai pelaksanaan pembelajaran dengan pembelajaran pendahuluan yaitu: mengucapkan salam, melakukan absensi, memotivasi siswa agar giat belajar, melakukan apersepsi, menyampaikan tujuan pembelajaran serta cakupan materi yang sedang diajarkan; 2) Selama pelaksanaan pembelajaran menggunakan kata-kata yang santun, luas dan mudah dimengerti oleh peserta didik; 3) Mengajar dengan menyesuaikan materi dengan kecepatan dan kemampuan peserta didik; 4) Menghargai setiap respon siswa; 5) Mengakhiri pelajaran tepat waktu dan menyampaikan salam penutup. 3. Observasi/Pengamatan Siklus II. Observasi atau pengumpulan data dari kegiatan penelitian ini dilakukan dengan cara: 1) Penilaian hasil belajar peserta didik merupakan pengumpulan informasi sebagai bukti tentang pencapaian pembelajaran yang telah dilakukan terhadap pengetahuan, sikap dan keterampulan dilakukan setelah tahap pelaksanaan pembelajaran, 2) Peneliti telah menyiapkan tes terlebih dahulu yang digunakan untuk mengukur kemampuan peserta didik, 3) Peneliti melakukan penilaian authentic atau penilaian yang sebenarnya atau apa yang mereka dapat tampulkan dengan sebenar-benarnya, 4) Melaksanakan tes dengan memperhatikan kemampuan individu peserta didik, ketepatan jawaban mengingat penilaian mrupakan wujud pelaksanaan tugas profesional, 5) Siswa yang termasuk tuntas diberikan kesempatan untuk memberitahukan kepada temannya yang belum tuntas tentang materi yang belum dikuasai. Dan 4. Refleksi mencakup hal-hal seperti analisis penjelasan keberhasilan dan pemaparan dalam bentuk tabel serta grafik.

\section{HASIL DAN PEMBAHASAN}

Hal-hal yang menjadi perencanaan dari penelitian ini adalah: 1) Memahami lebih dalam sintaks pembelajaran yang digunakan; 2) Membaca materi dengan seksama sebelum mengajar agar tidak dalam pelaksanaannya terjadi hal-hal yang kurang diinginkan; 3) Menyiapkan alat peraga serta alat-alat lain yang akan mendukung proses pembelajaran pada saat pelaksanaannya; 4) Kelemahan siswa yang tidak aktif dicermati, diperbaiki dengan memberi tugas yang mampu dikerjakan; 5) Merencanakan dalam penutupan pembelajaran akan melakukan hal-hal: membuat ringkasan/rangkuman, melakukan peninjauan terhadap apa yang belum dipahami peserta didik, mendemonstrasikan ulang hal-hal yang belum betul dipahami, mengekspresikan, memberi soal-soal, memberikan tindak lanjut seperti pekerjaan rumah atau tugas-tugas tertentu.

Refleksi merupakan kajian secara menyeluruh tindakan yang telah dilakukan berdasarkan data yang telah terkumpul, kemudian dilakukan evaluasi guna menyempurnakan tindakan. Refleksi menyangkut analisis, sintesis, dan penilaian terhadap hasil pengamatan atas tindakan yang dilakukan (Hopkin, 1993 dalam Suharsimi Arikunto, Suhardjono, Supardi, 2006: 80). Berdasarkan hasil analisis data awal ditemukan bahwa rata-rata nilai yang didapatkan oleh siswa selama pembelajaran yaitu 56, 25 . Sedangkan nilai ketuntasan minimum yaitu 60. Hal ini menunjukan bahwa masih banyak siswa yang tidak tuntas karena siswa yang kurang paham materi matematika. Rendahnya hasil belajar siswa pada siklus I disebabkan karena lingkungan peserta didik yang kurang mendukung untuk mereka aktif belajar, metode yang dipakai mengajar masih lebih banyak didominasi oleh ceramah sehinga materi belum maksimal dalam penyerapannya, kurangnya dukungan orang tua untuk mengarahkan anak-anaknya untuk lebih giat 
belajar, materi terlalu sulit, tidak menyentuh lingkungan hidup siswa sehari-hari dan guru kurang menguasai materi.

Pada siklus I ini telah rancangan yang matang, menggunakan metode yang bervariasi dengan menggabungkan berbagai metode. Tes prestasi belajar yang diberikan telah memforsir siswa untuk betulbetul dapat memahami apa yang sudah dipelajari. Nilai rata-rata siswa di siklus I sebesar 58,13 menunjukkan bahwa siswa sudah menguasai materi yang diajarkan walaupun belum begitu sempurna. Hasil ini menunjukkan peningkatan kemampuan siswa menguasai mata pelajaran Matematika Apabila dibandingkan dengan nilai awal siswa sesuai data yang sudah disampaikan yaitu rata-rata 56,25 dengan ketuntasan belajar 43,75 \%. Pada siklus I ini sudah terjadi peningkatan yaitu rata-rata kelas sudah dicapai 58,13 dengan ketuntasan belajar 62,50\%. Hasil dari tes prestasi belajar di siklus I telah menemukan efek utama bahwa penggunaan metode tertentu berpengaruh terhadap prestasi belajar siswa yang dalam hal ini adalah model Kooperatif Tipe Team Assisted Individualization Dengan Tutor Sebaya.

Tahap selanjutnya yaitu perancaaan siklus II. Kegiatan yang dilakukan pada siklus II yaitu memahami lebih dalam sintaks pembelajaran yang digunakan, merencanakan mengatur tempat duduk siswa agar terjadi interaksi antara yang pandai dengan yang kurang pandai, merencanakan pembelajaran yang menggunakan diskusi kelompok kecil yang dibantu dengan diskusi perorangan, membaca materi dengan seksama sebelum mengajar agar tidak dalam pelaksanaannya terjadi hal-hal yang kurang diinginkan, merencanakan kegiatan yang meksimal melalui kegiatan aktif bertanya, aktif memberi masukan, aktif memberi saran, dll. Pelaksanaan proses belajar mengajar pada Siklus II dibuat lebih matang. Media telah diupayakan agar menarik perhatian peseta didik dengan gambar-gambar yang menarik ditampilkan di layar monitor, metode tanya jawab multi arah dikuatkan agar siswa yang lemah dapat melihat dan mendengar jawaban-jawaban dari banyak arah, dominasi guru ditekankan semaksimal mungkin.

Pada Siklus II kekurangan dari pelaksanaan tindakan siklus II adalah yaitu kemampuan guru dalam menepati apa yang telah dibuat sesuai rancangan sering terganggu oleh singkatnya waktu pembelajaran, juga dipengaruhi oleh kemauan peserta didik yang bervariasi serta minat mereka yang berbeda-beda, materi terlalu sulit, tidak menyentuh lingkungan hidup siswa sehari-hari. Kelebihan yang ditemukan pada pelaksanaan tindakan siklus II adalah kebiasaan siswa untuk memberi masukan kepada teman-temannya yang lain sudah dilakukan oleh semua peserta didik, peneliti sudah melatih berkali-kali cara mengajar dengan model Kooperatif Tipe Team Assisted Individualization sebelum pembelajaran dilaksanakan, contoh-contoh sudah diupayakan cukup banyak, upaya agar peserta didik giat saling membantu sudah terlaksana, kelebihan yang lain bahwa model ini mampu menunjukkan kelebihankelebihan dan peningkatan prestasi sesuai harapan guru sebagai peneliti. Pada siklus II menunjukkan bahwa kemampuan siswa dalam mengikuti pelajaran sudah cukup baik. Hal ini terbukti dari rata-rata nilai siswa mencapai 75 dengan ketuntasan belajar mencapai 87,5\%. Hasil ini menunjukkan bahwa model Kooperatif Tipe Team Assisted Individualization Dengan Tutor Sebaya telah berhasil meningkatkan kemampuan siswa menempa ilmu sesuai harapan. Setelah dibandingkan nilai awal, nilai siklus I dan nilai siklus II, terjadi kenaikan yang signifikan, yaitu dari rata-rata nilai awal adalah 56,25 naik di siklus I menjad 58,13 dan di siklus II naik menjadi 75. Sehingga dapat disimpulkan bahwa Model Pembelajaran Kooperatif Tipe Team Assisted Individualiszation (TAI) dengan tutor sebaya dapat meningkatkan prestasi belajar matematika pada siswa. Hal ini disebabkan oleh beberapa faktor yaitu sebagai berikut.

Pertama, Model Pembelajaran Kooperatif Tipe Team Assisted Individualiszation (TAI) dengan tutor sebaya dapat memudahkan siswa dalam belajar matematika. Model pembelajaran Kooperatif tipe TAI memadukan antara pembelajaran individu dan pembelajaran kelompok (Ariani, 2017; Isa et al., 2017). Hal ini yang menyebabkan siswa mudah memahami materi pembeljaran terutama. Model pembelajaran kooperatif dapa merangsang siswa dalam belajar sehingga memudahkan siswa dalam memahami materi pembelajaran (Fauziyyah, 2018; Padmi, 2018; Sari, 2014; Witari, Putri, \& Rati, 2017). Aspek kognitif sangat ditekankan pada model ini sebagai pedoman atas kemampuan siswa baik pikiran imajinasi, analisis, prilaku maupun keterampilan yang dimiliki. Model pembelajaran Kooperatif Tipe Team Assisted Individualization Dengan Tutor Sebaya menempati tempat yang penting karena dapat mengaktifkan kemampuan siswa secara maksimal. Pembelajaran tipe TAI tersebut juga dapat meningkatkan kemampuan berpikir kritis dan aktivitas siswa untuk menjadi lebih aktif (Ariani, 2017; Hurriyah, 2017; Ngilamele et al., 2019).

Kedua, Model Pembelajaran Kooperatif Tipe Team Assisted Individualiszation (TAI) dengan tutor sebaya dapat meningkatkan semangat belajar siswa. Metode pembelajaran yang diterapkan oleh seorang guru berpengaruh terhadap prestasi belajarnya (Hwang, Yang, \& Wang, 2013; Nkhoma, Sriratanaviriyakul, \& Quang, 2017; Wang, Liu, \& Zhou, 2021). Model pembelajaran ini dapat meningkatkan semangat belajar siswa karena menekatkan keaktifan siswa dalam belajar. Adanya model pembelajaran ini dapat meningkatkan motivasi belajar siswa, melatih siswa untuk bekerja secara kelompok, dan juga dapat 
mengurangi anggapan bahwa pembelajaran itu sulit (Anika \& Fajar, 2020; Barnaba \& Asruddin, 2018; Jaziroh, 2019; Rosdiana, Kusmariyatni, \& Widiana, 2013). Pembelajaran TAI mengajak siswa dalam belajar mandiri, dan mengoptimalkan kemampuannya dalam mendapatkan informasi ilmiah yang dicari, melatih menjelaskan hasil temuannya dan dilatih untuk memecahkan masalah, tidak hanya menerima, mendengar, dan mengingat saja(Hurriyah, 2017; Isa et al., 2017; Ujianti, 2019). Penggunaan metode ini dapat membantu siswa berkreasi, bertindak aktif, bertukar pikiran, mengeluarkan pendapat, berargumentasi, bertukar informasi dan memecahkan masalah yang ada. Hal inilah yang dapat meningkatkan semangat belajar siswa.

Ketiga, Model Pembelajaran Kooperatif Tipe Team Assisted Individualiszation (TAI) dengan tutor sebaya dapat menciptakan suasana belajar yang menyenangkan. Model pembelajaran Kooperatif Tipe Team Assisted Individualization Dengan Tutor Sebaya merupakan model yang cocok bagi siswa apabila guru menginginkan mereka memiliki kemampuan berkreasi, berargumentasi, mengeluarkan pendapat secara lugas, bertukar pikiran, bekerja sama dan bekerja bersama, berargumentasi, mengingat (Farnika, Ikhsan, \& Sofyan, 2015; Hurriyah, 2017; Weni, Susanti, \& Jatmiko, 2016). Pengaruh yang ditimbulkan dari model yang diterapkan dalam proses pembelajaran membuktikan bahwa guru sudah tepat memilih metode dalam melaksanakan proses pembelajaran karena pemilihan metode dapat menciptakan suasana belajar yang menyenangkan (Siwi, Sudrajat, \& Wardana, 2019). Pertimbangan yang baik dalam melaksanakan sebuah penelitian adalah arah-arah yang benar sesuai aturan. Kegiatan pembelajaran yang dilakukan saat menerapkan model pembelajaran ini yaitu: 1) Memulai pelaksanaan pembelajaran dengan pembelajaran pendahuluan yaitu: mengucapkan salam, melakukan absensi, memotivasi siswa agar giat belajar, melakukan apersepsi, menyampaikan tujuan pembelajaran serta cakupan materi yang sedang diajarkan; 2) Selama pelaksanaan pembelajaran menggunakan kata-kata yang santun, luas dan mudah dimengerti oleh peserta didik; 3) Mengajar dengan menyesuaikan materi dengan kecepatan dan kemampuan peserta didik; 4) Menghargai setiap respon siswa; 5) Mengakhiri pelajaran tepat waktu dan menyampaikan salam penutup. Kegiatan inilah yang menyebabkan suasana belajar menjadi aktif dan menyenangkan.

Temuan penelitian sebelumnya menyatakan bahwa model pembelajaran Koopeartif Tipe TAI dapat meningkatkan hasil belajar siswa (Ariani, 2017; Hidayati et al., 2016; Ngilamele et al., 2019). Temuan penelitian lainnya juga menyatakan bahwa model pembelajaran Koopeartif Tipe TAI dapat meningkatkan semangat belajar siswa dan mencipatakan suasana belajar yang menyenangkan (Ariani, 2017; Prabaningrum \& Putra, 2019; Ujianti, 2019). Dapat disimpulkan bahwa model pembelajaran Koopeartif Tipe TAI dapat membantu siswa dalam belajar. Jabaran tersebut memberikan gambran bahwa model kooperatif tipe TAI akan membantu siawa untuk menemukan pengelamanya sendiri. Kelebihan model pembelajaran ini membuat beberapa peneliti melakukan penelitian untuk membuktikan efektifitas model pemelajaran Koopeartif Tipe TAI. Implikasi penelitian ini yaitu model pembelajaran Koopeartif Tipe TAI akan memudahkan guru dalam mengajar serta akan meningkatkan kemampuan siswa.

\section{SIMPULAN}

Model Kooperatif Tipe Team Assisted Individualization Dengan Tutor Sebaya telah berhasil meningkatkan kemampuan matematika pada siswa. Setelah dibandingkan nilai awal, penerapan Model Kooperatif Tipe Team Assisted Individualization Dengan Tutor Sebaya meningkatkan hasil belajar siswa sehingga model ini cocok diterapkan dalam pembelajaran. Direkomendasikan kepada guru untuk menggunakan model pembelajaran Kooperatif Tipe Team Assisted Individualization sehingga memudahkan siswa dalam belajar.

\section{DAFTAR RUJUKAN}

Andersen, T., \& Watkins, K. (2018). The value of peer mentorship as an educational strategy in nursing. Journal of Nursing Education, 57(4), 217-224. https://doi.org/10.3928/01484834-20180322-05.

Angela, T. (2014). Challenges to Meaningful Learning in Social Studies - The Key Competences as an Opportunity to Students' Active Participation. Procedia - Social and Behavioral Sciences, 128, 192197. https://doi.org/10.1016/j.sbspro.2014.03.142.

Anika, \& Fajar. (2020). Efektivitas Model Pembelajaran Kooperatif Tipe Make-A Match Dalam Meningkatkan Kompetensi Sikap Siswa dan Kompetensi Pengetahuan Siswa Pada Pelajaran IPS. Jurnal Ilmiah Sekolah $\quad$ Dasar, 4 80-85. https://doi.org/http://dx.doi.org/10.23887/jisd.v4i1.24047.

Ariani, T. (2017). Pembelajaran Kooperatif Tipe Team Assisted Individualization (TAI): Dampak Terhadap 
Hasil Belajar Fisika Siswa. Jurnal Ilmiah Pendidikan Fisika Al-Biruni, 6(2), 169. https://doi.org/10.24042/jipfalbiruni.v6i2.1802.

Arthaningsih, N. K. J., \& Diputra, K. S. (2018). Pengaruh Model Pembelajaran Kooperatif Tipe Two Stay Two Stray melalui Lesson Study terhadap Hasil Belajar Matematika. Journal of Education Technology, 2(4), 128-136. https://doi.org/http://dx.doi.org/10.23887/jet.v2i4.16424.

Barnaba, \& Asruddin. (2018). Peningkatan Penguasaan Kosakata Bahasa Inggris Melalui Media Anagram Dalam Metode Kooperatif Tipe Teams Games Tournament Improving the English Vocabulary Mastery Through Anagram Media in Cooperative Methods of Study Teams Games Tournament $\begin{array}{llll}\text { Type. Jurnal Prima 80-89. } & \text { 2(1), }\end{array}$ https://doi.org/https://doi.org/10.21831/jpe.v2i1.2646.

Bressington, D. T., Wong, W. kit, Lam, K. K. C., \& Chien, W. T. (2018). Concept mapping to promote meaningful learning, help relate theory to practice and improve learning self-efficacy in Asian mental health nursing students: A mixed-methods pilot study. Nurse Education Today, 60(February 2017), 47-55. https://doi.org/10.1016/j.nedt.2017.09.019.

Farnika, Ikhsan, \& Sofyan. (2015). Peningkatan Kemampuan Pemahaman Dan Pemecahan Masalah Matematis Sekolah Menengah Atas Dengan Model Pembelajaran Kooperatif Tipe Team Assisted Individualization. Jurnal Elemen Program Studi Matematika, 1(2), 144-152.

Fauziyyah, S. (2018). Implementasi Model Pembelajaran Kooperatif Tipe Teams Games Tournament (Tgt) Untuk Mengingkatkan Aktivitas Belajar Akuntansi. Jurnal Pendidikan Akuntansi Indonesia, 16(1), 73-81. https://doi.org/https://doi.org/10.21831/jpai.v16i1.20171.

Gabriele, K. M., Holthaus, R. M., \& Boulet, J. R. (2016). Usefulness of Video-Assisted Peer Mentor Feedback in Undergraduate Nursing Education. Clinical Simulation in Nursing, 12(8), 337-345. https://doi.org/10.1016/j.ecns.2016.03.004.

Han, J.-S., Baek, H. C., \& Jeong, A.-S. (2015). The Effects of Psychiatric Nursing Simulation on Anxiety and Self-confidence about Clinical Placement of Nursing Students. Journal of the Korea Academia$\begin{array}{llll}\text { Industrial Cooperation } & \text { Society, }\end{array}$ https://doi.org/10.5762/kais.2015.16.11.7812.

Hidayati, I., Deswita, H., \& Afri, L. E. (2016). Pengaruh Model Pembelajaran Kooperatif Tipe Teams Assisted Individualization (TAI) Terhadap Hasil Belajar Matematika Siswa Kelas VII SMPN 3 UJUNG BATU. Jurnal Pendidikan Matematika, 2(2), 1-6.

Hurriyah. (2017). Penerapan Model Kooperatif Tipe TAI ( Team Assisted Individualization ) Untuk Meningkatkan Pemahaman Konsep Dalam Pembelajaran Fisika Kelas X MIA. Natural Science Journal, 3(1), 328-335. https://doi.org/https://doi.org/10.15548/nsc.v3i1.403.

Hwang, G. J., Yang, L. H., \& Wang, S. Y. (2013). A concept map-embedded educational computer game for improving students' learning performance in natural science courses. Computers \& Education, 69. https://doi.org/https://doi.org/10.1016/j.compedu.2013.07.008.

Isa, M., Khaldun, I., \& Halim, A. (2017). Penerapan Model Pembelajaran Kooperatif Tipe Tai Untuk Meningkatkan Penguasaan Konsep Dan Berpikir Kritis Siswa Pada Materi Hidrokarbon. Jurnal IPA \& Pembelajaran IPA, 1(2), 213-223. https://doi.org/10.24815/jipi.v1i2.9696.

Jaziroh, A. (2019). Pengaruh Model Pembelajaran Kooperatif Tipe Team Accelerated Instruction (Tai) Terhadap Kemampuan Pemecahan Masalah Dalam Pembelajaran Matematika Materi Pola Bilangan. Hipotenusa: Journal of Mathematical Society, 1(1), 27-32. https://doi.org/10.18326/hipotenusa.v1i1.3283.

Kurniawati, K. R. A., Budiyono, \& Saputro, D. R. S. (2017). Penerapan Model Pembelajaran Kooperatif Tipe Jigsaw Dan Numbered Heads Together Ditinjau Dari Kecerdasan Interpersonal Siswa Pada Pokok Bahasan Bangun Ruang Sisi Datar. Jurnal Pendidikan Matematika, 11(1). https://doi.org/10.22342/jpm.11.1.3948.15-28.

Laksmi, N. P. R. A., Wiarta, I. W., \& Made Putra. (2017). Pengaruh Model Pembelajaran Kooperatif Tipe Team Assisted Individualization Terhadap Kompetensi Pengetahuan Matematika Siswa Kelas Iv. Mimbar Pgsd, 5(2), 1-10.

Lisdayanti, N. P., Ardana, I. K., \& Suryaabadi, I. B. G. (2014). Pengaruh Model Pembelajaran Kooperatif Talking Stick Berbantuan Media Gambar Terhadap Hasil Belajar IPA Siswa Kelas V Sd Gugus 4 Baturiti. Journal Mimbar PGSD Universitas Pendidikan Ganesha Jurusan PGSD, 2(1). https://doi.org/http://dx.doi.org/10.23887/jjpgsd.v2i1.1962.

Muhammad, H. M. (2018). Keefektifan Model Pembelajaran Tebak Kata Terhadap Hasil Belajar Pada Tema 7 "Indahnya Keragaman Di Negeriku" Siswa Kelas Iv. Mimbar Ilmu, 23(3), 200-207. https://doi.org/10.23887/mi.v23i3.16436.

Muliandari, P. T. V. (2019). Pengaruh Model Pembelajaran Kooperatif Tipe NHT ( Numbered Head Together ) Terhadap Hasil Belajar Matematika. International Journal of Elementari Education, 
3(2), 132-140. https://doi.org/http://dx.doi.org/10.23887/ijee.v3i2.18517.

Ngilamele, M., Laamena, C. M., \& Palinussa, A. (2019). Efektifitas Model Pembelajaran Kooperatif Tipe Tai (Teams Assited Individualization) Terhadap Hasil Belajar Materi Himpunan Pada Siswa Smp Maria Mediatrix Ambon. Journal of Honai Math, 2(1), 13-24. https://doi.org/10.30862/jhm.v2i1.51.

Nkhoma, M., Sriratanaviriyakul, N., \& Quang, H. L. (2017). Using case method to enrich students' learning outcomes. Active Learning in Higher Education, 18(1). https://doi.org/https://doi.org/10.1177\%2F1469787417693501.

Nurmahmidah. (2017). Penerapan Model Pembelajaran Kooperatif Tipe Teams Games Tournament (Tgt) Pada Pokok Bahasan Peluang Sebagai Upaya Meningkatkan Prestasi Dan Motivasi Belajar Matematika Siswa Kelas X Mia 2 Sma Negeri 1 Sedayu. Jurnal Mercumatika, 1(2), 65-72. https://doi.org/DOI:https://doi.org/10.26486/mercumatika.v1i2.252.

Oh, E. (2019). Research on the effective of peer instruction and students' involvement. Asia-Pacific of Multimedia Services Convergent with Art Humanities, and Sociology, 9, 199-208. https://doi.org/https://doi.org/10.35873/ajmahs.

Padmi, I. A. N. (2018). Peningkatan Aktivitas Pembelajaran Pendidikan Kewarganegaraan Materi Perlindungan dan Penegakan Hukum dengan Metode Kooperatif Tipe STAD Pada Siswa Kelas XII IPS 2 di SMAN 3 Mataram. Jurnal Kependidikan, 4(2), 152-157. https://doi.org/https://doi.org/10.33394/jk.v4i2.1123.

Prabaningrum, I. G. A. I., \& Putra, I. K. A. (2019). Pengaruh Model Pembelajaran Kooperatif Team Assisted Individualization Berbantuan Media Semi Konkret Terhadap Kompetensi Pengetahuan Matematika. Jurnal Ilmiah Sekolah Dasar, 3(4), 414. https://doi.org/10.23887/jisd.v3i4.21775.

Puspitawangi, K. R., Wibawa, I. M. C., \& Pudjawan, K. (2017). Pengaruh Model Pembelajaran Kooperatif Tipe Talking Stick Berbantuan Media Audio Visual Terhadap Hasil Belajar Ips. MIMBAR PGSD Undiksha, 5(2).

Rosdiana, Kusmariyatni, \& Widiana. (2013). Pengaruh Model Pembelajaran Kooperatif Tipe Paired Storytelling Berbantuan Media Audio Visual Terhadap Keterampilan Menyimak Bahasa Indonesia Siswa Kelas V SD. Mimbar PGSD Undiksha, 1(1). https://doi.org/http://dx.doi.org/10.23887/jjpgsd.v1i1.826.

Sari, M. K. (2014). Pengaruh Metode Kooperatif Jigsaw Terhadap Prestasi Belajar Mata Pelajaran IPS Pada Siswa Kelas III. Jurnal Pendidikan Dasar Dan Pembelajaran, 4(2), 113-144. https://doi.org/http://doi.org/10.25273/pe.v4i02.313.

Seika Ayuni, I. G. a. P. A., Kusmariyatni, N., \& Japa, I. G. N. (2017). Pengaruh Model Pembelajaran Talking Stick Berbantuan Media Question Box Terhadap Hasil Belajar Ipa Kelas V. Journal of Education Technology, 1(3), 183. https://doi.org/10.23887/jet.v1i3.12503.

Shoffa, S., \& Suprapti, E. (2017). Peningkatan Hasil Belajar Mahasiswa pada Mata Kuliah Metode Numerik dengan Model Pembelajaran Kooperatif Jigsaw. MUST: Journal of Mathematics Education, Science and Technology, 2(2), 178-188.

Siwi, Sudrajat, \& Wardana. (2019). Keefektifan Model Team Assisted Individualization Berbantu Media Corong Hitung Terhadap Hasil Belajar Matematika. Mimbar PGSD Undiksha, 7(2), 128-134.

Stone, R., Cooper, S., \& Cant, R. (2013). The Value of Peer Learning in Undergraduate Nursing Education: A Systematic Review. ISRN Nursing, 2013(i), 1-10. https://doi.org/10.1155/2013/930901.

Suaeb, S., Degeng, I. N. S., \& Amirudin, A. (2018). Meningkatkan Hasil Belajar IPS Siswa Kelas V melalui Penerapan Pembelajaran Kooperatif Model Teams Games Tournament ( TGT ) Berbantuan Media Tebak Gambar. Jurnal Pendidikan: Teori, Penelitian, Dan Pengembangan, 3(1), 146-154. https://doi.org/http://dx.doi.org/10.17977/jptpp.v3i1.10435.

Ujianti, C. (2019). Penerapan Model Pembelajaran Kooperatif Tipe TAI (Team Assisted Individualization) untuk Meningkatkan Hasil Belajar Siswa pada Mata Pelajaran Matematika. Jurnal Cakrawala Pendas, 4(1), 1-14. https://doi.org/10.1017/CB09781107415324.004.

Wang, Y., Liu, H., \& Zhou, Y. (2021). Development of a deep learning-based model for the entire production process of steam-assisted gravity drainage (SAGD). Fuel, 287. https://doi.org/https://doi.org/10.1016/j.fuel.2020.119565.

Weni, Susanti, \& Jatmiko. (2016). Implementasi Model Pembelajaran Kooperatif Tipe Tai (Team Assisted Individualization) Untuk Meningkatkan Hasil Belajar Fisika Siswa Sma Pada Materi Elastisitas. Jurnal Penelitian Fisika Dan Aplikasinya (JPFA), 6(1), 26-33.

Witari, I. G. A., Putri, M., \& Rati. (2017). Pengaruh Model Pembelajaran Kooperatif Tipe Numbered Head Together Terhadap Hasil Belajar IPA Siswa Kelas IV. MIMBAR PGSD Undiksha, 5(2), 1-10. https://doi.org/http://dx.doi.org/10.23887/jjpgsd.v4i1.7445. 